\title{
Bright light enhances the efficiency of physical activity in combination with a restrictive diet
}

\author{
Boris B. Pinkhasov*, Vera G. Selyatitskaya, Ani R. Karapetyan \\ Siberian Branch of Russian Academy Medical Sciences, Scientific Centre of Clinical and Experimental Medicine, Novosibirsk, Russia; \\ *Corresponding Author: pin@soramn.ru, pin71nsk@mail.ru
}

Received 7 November 2013; revised 10 December 2013; accepted 21 December 2013

Copyright (C) 2014 Boris B. Pinkhasov et al. This is an open access article distributed under the Creative Commons Attribution License, which permits unrestricted use, distribution, and reproduction in any medium, provided the original work is properly cited. In accordance of the Creative Commons Attribution License all Copyrights @ 2014 are reserved for SCIRP and the owner of the intellectual property Boris B. Pinkhasov et al. All Copyright (C) 2014 are guarded by law and by SCIRP as a guardian.

\section{ABSTRACT}

The purpose of this study was to analyze the effectiveness of measures aimed at correcting obesity in women and including bright light exposure during aerobic exercise combined with a restrictive diet. A one-stage, randomized study involved 80 obese women aged 20 to 58 years. The inclusion criterion for selecting participants for this research was the presence of primary alimentary-constitutional obesity with body mass index equal to or higher than $30 \mathrm{~kg} / \mathrm{m}^{2}$. All the women were distributed into three groups according to the set of applied treatments. In Group 1, the women were on a restrictive diet; in Group 2, the restrictive diet was accompanied with daily aerobic exercise; in Group 3, women were exposed to bright light during exercise. Before and after the treatment course ( 3 weeks), body weight, waist and hip circumferences were measured; fat amount was determined by the impedancemetry method; and oxygen consumption was determined by indirect calorimetry. Women in Group 1 had reduced body weight, waist and hip circumferences, fat mass and oxygen consumption. Similar changes were identified in women of Group 2, but weight loss was greater, and the level of oxygen consumption increased as compared to the baseline. In women of Group 3, weight loss and increased oxygen consumption were more pronounced than in those of Group 2. The number of metabolic equivalents (MET) in women of Group 3 increased to nearly 1, which corresponded to the value of this index that reflected the resting metabolic rate in patients with normal body weight. Thus, exposure to bright full-spectrum light increases energy metabolism and enhances the effectiveness of exercises, despite prolonged food restriction, which is one of the mechanisms to improve the efficiency of obesity correction.

\section{KEYWORDS}

Obesity; Bright Light; Physical Activity; Restrictive Diet

\section{INTRODUCTION}

Overweight and obesity represent a rapidly growing threat to the health of populations in an increasing number of countries [1]. Obesity, especially central obesity, is becoming recognized as one of the most important non-communicable diseases' risk factors. Obesity comorbidities include coronary heart disease, hypertension and stroke, certain types of cancer, non-insulin-dependent diabetes mellitus, gallbladder disease, nonalcoholic steatosis, dispipidaemia, gastrointestinal diseases, osteoarthritis and gout, asthma, pulmonary diseases, including sleep apnoea, polycystic ovary syndrome, severe urinary incontinence and others diseases [1-5]. In addition to its substantial impact on physical health, obesity is also associated with increased risks of psychiatric or mental disorders such as depression, anxiety, manias, panic attacks and suicidal ideation [6-9].

In recent years, it has become clear that adipose tissue accumulating in obesity is not only a passive receptacle of lipids. Adipose tissue releases a large number of bioactive mediators that influence not only body weight homeostasis but also development of metabolic and cardiovascular diseases [10]. With increasing fat mass, the development of adipose tissue inflammation and dysfunction, secretion of adipose tissue derived adipokines, is significantly altered towards a proinflammatory, di- 
abetogenic and atherogenic pattern [11,12]. This suggests that obesity itself is also a chronic, complex, multifactorial disease, resulting from the interaction of genetics, environment and lifestyle, which requires a longterm multi-stage treatment.

The prevalence of obesity has been shown to increase dramatically in step with the change of lifestyles and increases in energy-dense foods intake. Epidemiologic studies have begun to show links between adiposity and behaviors such as television (TV) watching, alcohol intake and sleep deprivation. They are not merely correlated with obesity but likely contribute to it by encouraging excessive eating [13]. Of the different sedentary behavior types (TV viewing, computer time, reading, music/radio listening and other relaxation), in particular, TV viewing was most consistently related to higher body mass index and waist circumference, both in men and women [14]. Alcohol may contribute to positive energy balance via its additive effects on total energy intake and by short-term appetite stimulation $[15,16]$. Sleep curtailment in humans alters multiple metabolic pathways, leading to more insulin resistance, possibly decreased energy expenditure, increased appetite and immunological changes [17].

In this regard, the main approaches to obesity treatment include the use of restrictive diets, which should be supported by a suitable physical activity and possibly by behavioral therapy (frequently referred to as lifestyle modification) [18]. However, it is important to distinguish between active lifestyle and physical fitness [19]. It has been shown that drug trials which include dietary advice, plus exercise and behavior therapy are the most effective method as compared to their separate use [20]. According to the US guidelines [21], in more complex cases, pharmacological therapies can be used for periods ranging from 6 months to 1 year. Otherwise, surgery is the only recommended treatment in extreme cases for those patients suffering from acute obesity (BMI > 35) and other associated pathologies, that is, inpatients having a high mortality risk or who do not respond to other treatments.

Though a great number of schemes, methods and approaches used both separately and in a complex have been developed for obesity treatment through lifestyle modification, the effectiveness of obesity treatment still remains rather low [22-24]. For instance, in [24], the authors write that obesity treatment includes some of the barriers to successful weight loss: 1) unrealistic expectations of success; 2) high attrition rates; 3) cultural norms of self-acceptance in terms of weight and beliefs of fat being healthy; 4) neighborhood attributes such as a lack of well-stocked supermarkets rather than the presence of convenience stores with low-quality foods; and 5) the perception of the neighborhood as less safe and with low walkability.

The difficulties of obesity treatment also include the unavailability of information on the principles of rational nutrition and optimal physical activity as well as subjective difficulties in implementing the recommendations in this area. The fight against these causes of low effectiveness of obesity treatment is aimed at the establishment of a continuous dynamic monitoring of the implementation of recommendations. This work is carried out most effectively under extended programs of communication of health professionals with obese participants of the programs $[25,26]$.

Depression is a serious factor decreasing the effectiveness of obesity treatment through lifestyle modification. Accumulating evidence now suggests that lifestyle factors such as diet quality contribute to a number of mental diseases [27] and play an important role in the risk and genesis of depression specifically [28]. Dietary restrictions are combined with the development of the so-called "diet-related depression", and larger weight losses are associated with the increased risk of depression [29]. Patients with emotional eating disorders are most susceptible to the development of "the diet-related depression" [29], and these are most typical for obese people. Previously, we demonstrated that the incidence of emotional eating disorders among obese women was 43\% [30]. In some patients, "the diet-related depression" develops even during simultaneously conducted psychological correction and is the reason of decreased effectiveness and/or refusal to continue obesity treatment. In addition, depression was found to be predictive of developing obesity [31]. At the same time, lifestyle modification programs, which incorporated exercise with dietary instruction and behavior therapy, were found to induce reductions in symptoms of depression [32].

The development of "the diet-related depression" can be associated with a decreased level of energy metabolism, which occurs in obesity treatment using various diets. Such relationship is clearly seen in patients with seasonal affective disorders (SAD). In women with SAD, we revealed a relationship between low level of energy metabolism with depression and a number of atypical vegetative symptoms such as increased appetite and weight gain, preference of carbohydrate-rich food, hypersomnia and difficult morning awakening. The use of bright artificial light as a method of treatment resulted in the disappearance of both depressive and atypical vegetative symptoms, against the background of an elevated level of energy metabolism [33].

The significance of light for the human organism and especially for the mental health is well-established for a long time. In the last years, several clinical trials could demonstrate the therapeutic efficacy of bright light therapy for different neurological and psychiatric disorders 
such as sleep disorders, non-seasonal affective disorders or dementia [34,35].

Our previous findings suggest the possibility of increasing the effectiveness of obesity treatment by including the exposure of the study participants to the bright full-spectrum artificial light in the correction program. In this regard, the study sought to compare the effects of a diet alone, a diet combined with exercise and a diet combined with exercise performed under conditions of the body exposure to bright artificial light on the intensity of energy metabolism and body weight of obese women. Exercise was used because, on the one hand, it increased energy expenditures [19] and, on the other hand, showed positive properties in treating depressive disorders [36]. In addition, diets are generally used together with exercise in obesity treatment [18].

\section{METODS}

\subsection{Subjects}

The one-stage, randomized study involved 80 obese european whites women aged 20 to 58 years (median age $37.1 \pm 7.4$ years). The inclusion criterion for selecting participants for this research was presence primary alimentary-constitutional obesity with body mass index equal to or higher than $30 \mathrm{~kg} / \mathrm{m}^{2}$. The exclusion criteria were morbid and neuroendocrine obesity, diabetes mellitus 1 and 2 types, acute heart and pulmonary diseases, malignancy, acute infections and inflammatory diseases. The work was conducted at the Clinical Research and Practical Center of Endocrine and Metabolic Disorders Correction (Novosibirsk, Russia, $\mathrm{N}^{\circ} 55$ ). All patients involved in the study gave their informed consent to participate in the investigation, which complied with the ethical standards developed in accordance with the World Medical Association Declaration of Helsinki on Ethical Principles for Medical Research Involving Human Subjects, and a permit was obtained from the Local Biomedical Ethics Committee.

\subsection{Applied Treatments}

Applied Treatments. The course of treatment lasted for 3 weeks and consisted of a restrictive diet, aerobic exercise and exposure to bright full-spectrum light during exercise.

As shown in Table 1, all of women were distributed into three groups according to the set of applied treatments.

In women of Group 1, BMI was $36.2 \pm 1.6 \mathrm{~kg} / \mathrm{m}^{2}$, and in women of Group 2 it was $35.9 \pm 1.6 \mathrm{~kg} / \mathrm{m}^{2}$, and in Group 3 BMI was $37.7 \pm 2.2 \mathrm{~kg} / \mathrm{m}^{2}$. Thus, women of all three groups had comparable BMI values and, consequently, degrees of obesity.

During the study, all of women additionally received
Table 1. Women groups in depending on the type of applied treatment.

\begin{tabular}{cccc}
\hline & Group 1 & Group 2 & Group 3 \\
\hline Restrictive diet & $(\mathrm{n}=26)$ & $(\mathrm{n}=30)$ & $(\mathrm{n}=24)$ \\
Exercise & + & + & + \\
Lighting Conditions & - & + & + \\
\hline
\end{tabular}

daily aquatic physiotherapy (Charcot power shower) and electromyo stimulation.

\subsubsection{Restrictive Diet}

A standard course of restrictive diet included a very low calorie liquid diet (400 - $800 \mathrm{kcal}$ per day) during the first five days of the study followed by a transition to a low calorie diet (1000 - $1200 \mathrm{kcal}$ per day) to the end of the study. As the study was comparatively short, a very low calorie liquid diet was used during the first days of the study to achieve a greater effect of the restrictive diet on the energy balance. The transition from a very low calorie liquid diet to a low calorie diet was caused by the need to prevent cases of binge eating at the end of the study, against the background of a developing "diet-related depression" [29], which are more typical of individuals on a very low calorie liquid diet [37].

\subsubsection{Exercise}

Daily aerobic exercise included treadmill walking for 40 minutes in the morning. Aerobic exercise was selected individually based on heart rate (HR), which should be between $55 \%$ and $65 \%$ of its maximal value during walking. The maximal HR value was calculated according to the formula: HR $\max =220-$ age in years.

\subsubsection{Light Treatment}

While walking on the treadmill, daily sessions of exposure to full-spectrum light were conducted simultaneously. A switched on fluorescent lamp with light intensity of 2000 - 2500 lux, the Innsol Mesa lamp (Innojok Ltd., Finland) was at a distance of $120-140 \mathrm{~cm}$ from the face at 40-minute light exposure.

\subsection{Anthropometric Measurements}

Anthropometric measurements including height, body weight, waist and hip circumferences were obtained using standardized procedures. Body weight was measured using medical balance to the nearest $100 \mathrm{gm}$, height with the help of stadiometer to the nearest $5 \mathrm{~mm}$. Waist circumference $(\mathrm{cm})$ and hip circumference $(\mathrm{cm})$ were determined using measuring tape to the nearest $5 \mathrm{~mm}$ as described in the WHO Guidance (2008) [38]. Body mass 
index (BMI) was calculated as weight divided on height squared $\left(\mathrm{kg} / \mathrm{m}^{2}\right)$. The amount of fat in the body was determined by hand-to-hand bioelectrical impedancemetry using the Omron BF 302 set (OMRON Corporation, Japan). Anthropometric measurements were performed before and after a 3-week course of treatment.

\subsection{Oxygen Consumption Measurements}

Resting energy expenditure was assessed by an indirect calorimetry system that measured resting oxygen uptake (using the Metabolic Analyzer-Deltatrac, Sensor Medica Corp.). During oxygen consumption measuring, the women were in a comfortable and thermo regulated $\left(22^{\circ} \mathrm{C}-24^{\circ} \mathrm{C}\right)$ room where only the investigator and the patient were present. The measurements were performed in the morning before breakfast; the necessary requirement was a 30-minute rest before the start of the study. Oxygen consumption was determined as $\mathrm{ml} / \mathrm{min}$ followed by the calculation per $1 \mathrm{~kg}$ of body weight. The number of metabolic equivalents of tasks (MET) was calculated as a characteristic of the resting metabolic rate [39] and expressed as $\mathrm{kcal} / \mathrm{kg}$ of body weight per hour. Oxygen consumption was measured before and after a 3-week course of treatment.

\subsection{Statistical Analysis}

Statistical data processing was performed using the Statistica 6.0 program (StatSoft, USA). In the text, Tables 2 and 3 the results are presented as mean indicator values and the standard deviation (Mean $\pm \mathrm{SD}$ ); the comparative analysis was performed using the KruskalWallis test for multiple comparisons and the Mann-Whitney test for paired comparisons. The changes in all the measured parameters were calculated as the difference between the individual values of parameters before and after the procedures followed by the calculation of the Mean \pm SD for all parameters in each group. The Wilcoxon signed-rank test was used for comparative analysis of repeated measurements. The minimum probability of the null hypothesis validity was accepted at the $5 \%$ sig-

Table 2. Women anthropometric parameters before and after the course of treatment.

\begin{tabular}{|c|c|c|c|c|c|c|c|}
\hline Treatment & & Group $1(n=26)$ & Group $2(n=30)$ & Group $3(n=24)$ & & P-value & \\
\hline & & Mean \pm SD & Mean \pm SD & Mean \pm SD & $1-2$ & $1-3$ & $2-3$ \\
\hline Age (years) & & $40.4 \pm 6.1$ & $41.1 \pm 5.8$ & $39.3 \pm 6.7$ & 0.662 & 0.546 & 0.295 \\
\hline Weight (kg) & before & $91.5 \pm 14.7$ & $95.5 \pm 13.6$ & $90.5 \pm 10.3$ & 0.107 & 0.749 & 0.128 \\
\hline$P$ value & & $<0.001$ & $<0.001$ & $<0.001$ & & & \\
\hline Change in weight (kg) & & $-3.1 \pm 1.1$ & $-4.3 \pm 1.2$ & $-4.9 \pm 1.1$ & $<0.001$ & $<0.001$ & $<0.001$ \\
\hline \multirow[t]{2}{*}{ Waist circumference (cm) } & before & $100.3 \pm 11.5$ & $97.9 \pm 9.9$ & $97.8 \pm 7.4$ & 0.599 & 0.793 & 0.841 \\
\hline & after & $94.8 \pm 11.2$ & $91.3 \pm 8.7$ & $91.7 \pm 6.7$ & 0.371 & 0.724 & 0.694 \\
\hline$P$ value & & $<0.001$ & $<0.001$ & $<0.001$ & & & \\
\hline \multicolumn{8}{|l|}{ Change in waist } \\
\hline Circumference (cm) & & $-5.4 \pm 2.3$ & $5.3 \pm 2.3$ & $5.3 \pm 2.3$ & 0.939 & 0.875 & 0.821 \\
\hline \multirow[t]{2}{*}{ Hip circumference $(\mathrm{cm})$} & before & $119.4 \pm 15.1$ & $119.0 \pm 8.3$ & $114.3 \pm 7.0$ & 0.450 & 0.236 & 0.033 \\
\hline & after & $114.5 \pm 11.4$ & $115.1 \pm 5.1$ & $109.7 \pm 6.5$ & 0.190 & 0.200 & 0.005 \\
\hline$P$ value & & $<0.001$ & $<0.001$ & $<0.001$ & & & \\
\hline \multicolumn{8}{|l|}{ Change in hip } \\
\hline Circumference (cm) & & $-3.9 \pm 1.7$ & $-3.6 \pm 1.4$ & $-4.1 \pm 1.7$ & 0.489 & 0.714 & 0.523 \\
\hline Fat mass (kg) & before & $37.5 \pm 8.5$ & $40.1 \pm 8.3$ & $36.1 \pm 7.0$ & 0.092 & 0.658 & 0.060 \\
\hline$P$ value & & $<0.001$ & $<0.001$ & $<0.001$ & & & \\
\hline Change in fat mass (kg) & & $-2.3 \pm 1.1$ & $-2.6 \pm 1.1$ & $-2.8 \pm 1.0$ & 0.149 & 0.033 & 0.363 \\
\hline
\end{tabular}


Table 3. The level of oxygen consumption before and after the course of treatment.

\begin{tabular}{|c|c|c|c|c|c|c|c|}
\hline \multicolumn{2}{|l|}{ Treatment } & \multirow{2}{*}{$\begin{array}{c}\text { Group } 1(\mathrm{n}=26) \\
\text { Mean } \pm \text { SD }\end{array}$} & \multirow{2}{*}{$\begin{array}{c}\text { Group } 2(\mathrm{n}=30) \\
\text { Mean } \pm \text { SD }\end{array}$} & \multicolumn{2}{|c|}{ Group $3(n=24)$} & \multicolumn{2}{|c|}{ P-value } \\
\hline & & & & Mean \pm SD & $1-2$ & $1-3$ & $2-3$ \\
\hline $\begin{array}{l}\text { Oxygen consumption } \\
\qquad(\mathrm{ml} / \mathrm{min})\end{array}$ & after & $232.8 \pm 27.4$ & $279.7 \pm 33.1$ & $254.4 \pm 33.2$ & 0.007 & 0.001 & 0.003 \\
\hline \multicolumn{2}{|l|}{$\mathrm{P}$ value } & $<0.001$ & $<0.001$ & $<0.001$ & & & \\
\hline \multicolumn{2}{|c|}{$\begin{array}{c}\text { Change in oxygen } \\
\text { consumption (ml/min) }\end{array}$} & $-16.6 \pm 11.4$ & $12.2 \pm 18.9$ & $28.6 \pm 13.1$ & $<0.001$ & $<0.001$ & $<0.001$ \\
\hline \multirow{2}{*}{$\begin{array}{l}\text { Metabolic equivalent } \\
\text { (kcal/kg/hour) }\end{array}$} & before & $0.79 \pm 0.14$ & $0.74 \pm 0.11$ & $0.80 \pm 0.12$ & 0.139 & 0.496 & 0.044 \\
\hline & after & $0.77 \pm 0.13$ & $0.81 \pm 0.13$ & $0.94 \pm 0.14$ & 0.308 & $<0.001$ & $<0.001$ \\
\hline \multicolumn{2}{|l|}{$P$ value } & $<0.011$ & $<0.001$ & $<0.001$ & & & \\
\hline
\end{tabular}

nificance level $(\mathrm{p}<0.05)$.

\section{RESULTS}

After a 3-week the diet course, a significant reduction of body weight, waist and hip circumstances as well as adipose tissue mass was observed in women of Group 1 (Table 2). However, in this group of women, along with positive effects as changed values of the above anthropometric parameters, negative dynamics were observed in the level of oxygen consumption (Table 3).

In women of Group 2, for whom dietary effects were accompanied by exercise (treadmill walking), the values of the participants' body weight, circumference parameters and adipose tissue mass also decreased, and body weight reduction was greater than that in women of Group 1 (Table 2). The level of oxygen consumption by women of Group 2 increased as compared to the baseline, increased number of metabolic equivalents per $1 \mathrm{~kg}$ of body weight was also observed (Table 3 ). Thus, the use of exercise in a complex scheme of body weight correction resulted in more expressed dynamics of body weight reduction, which is consistent with literature data [19].

In women of Group 3, for whom, besides the diet and exercise, sessions of exposures to bright full-spectrum light during treadmill walking were additionally included in the general scheme of treatment. Body weight reduction was more expressed after a 3-week course of treatment in these women. The value of such an index as the change of body weight significantly differed from the corresponding values for Groups 1 and 2 (Table 2). The value of the loss of the fat component in women of Group 3 significantly differed from the value of the corresponding index in women of Group 1. The above changes in anthropometric indices in women of Group 3 were consistent with an increased level of oxygen consumption as compared to the values of the corresponding index in women of Groups 1 and 2. MET number increased practically to 1 , which corresponds to the value of this index that reflects the resting metabolic rate in individuals with normal body weight [40].

The women of the three groups did not differ from each other in the dynamics of the values of circumference indices; it can be seen that irrespective of the scheme of treatment, the women's waist circumference reduced to a greater extent than the hip circumference. This can be caused by the fact that abdominal adipose tissue is more metabolically active than the subcutaneous depot of the gluteofemoral area [41,42].

\section{DISCUSSION}

The results of the carried out research show that inclusion of bright light in a complex scheme of obesity correction in women increases the effectiveness of standard measures such as a low calorie diet in combination with aerobic exercise aimed at body weight reduction.

What can be the reason of such effect of light? In women of Group 1, whose scheme of obesity correction included only a diet restriction, in 3 weeks reduced oxygen consumption was revealed (Table 3), which indicates a slower metabolism at rest and suggests slowing of the basal metabolism [39]. Reduced energy metabolism can be considered as an adaptive reaction of the body onto the calorie restriction diet. In [43] it has been shown that suppression of resting metabolic rate out of proportion to the loss of body weight and fat-free mass may occur through a phenomenon known as adaptive thermogenesis or metabolic adaptation.

In women of Group 2, in whose scheme of obesity correction the calorie restriction was accompanied by exercise, the level of oxygen consumption increased as compared to the baseline (Table 3). It is known that physical activity is the main determinant of total energy 
expenditure and has been suggested to play a key role in body weight regulation. It was shown that a weight loss program consisting of a diet restriction and vigorous exercise helped to preserve fat-free mass and maintain resting metabolic rate [44]. Our results are consistent with the presented findings.

In women of Group 3, the scheme of obesity correction was accompanied by light exposure during exercise. The main elements of different schemes of obesity correction are diet restrictions aimed at limiting the supply of nutrients to the body and increasing motor activity contributing to increased consumption of excessive amounts of energy substrates in the body. Reduced body weight in groups of patients who used the combination of a diet restriction and exercise was greater than in individuals using only a diet restriction [14]. We have already discussed the question of the need for exercise for the preservation of fat-free mass [44]. In this regard, to verify the possibility of increasing the effectiveness of exercise due to light exposure, groups of women were formed for the comparative study of a diet restriction alone, a diet in combination with exercise and a diet in combination with exercise and light exposure.

The combination of exercise with sessions of bright light exposure caused a significantly greater increase of oxygen consumption in women of Group 3 than in women of Group 2. It could be suggested that exposures to bright full-spectrum light stimulate basal metabolism and, correspondingly, stimulate oxygen consumption. In women of Group 3, a greater reduction of body weight was observed as compared to the value of this index in women of Groups 1 and 2, and that of fat mass as compared to the value of this index in women of Group 1. Samples were limited in number, but the identified effects are confirmed by the results of our studies [33] and the works of other authors $[45,46]$.

In the work of Canadian researchers [45] based on evidence of the link between bright light, serotonin, mood, and food intake, it has been suggested that bright light therapy can improve weight loss. Overweight and obese subjects were assigned to 6 weeks of moderate exercise with or without bright light treatment. Is the first to show that bright light treatment during exercise impacted body composition by significantly reducing body fat after only a 6-week period. There was also a trend toward a greater reduction in body weight in the bright light treatment group, but this did not reach significance. The authors suggest that serotonergic pathways may play a role in fat intake, and this may provide one explanation for the findings of this study. Changes in energy expenditure may also have accounted for the findings in this study. All subjects were required to exercise at the same level (i.e., at a 65\% heart rate reserve) and all subjects used identical stationary bicycles, but those in the bright light group may have been more active outside. In the cited work [45], the authors write that it is not known whether changes in amounts consumed or eating pattern among those treated with the bright light accounted for the change in body fat mass.

In our study, a significant reduction of not only fat mass but also that of body weight was observed in women of Group 3 much earlier, already 3 weeks after the start of the course of obesity correction including a diet and exercise and accompanied by light exposure. Consequently, bright light exposure stimulates a reduction of not only fat mass but also that of body weight, though against the background of a diet restriction.

In [46], like in our study, the authors used a shorter 3 week in-home session of morning bright light treatment to verify the possibility of obesity correction using bright light. In this study, like in [45], with light, compared to the placebo session, weight did not reduce significantly, but percentage fat, fat mass, and appetite were significantly lower (average fat reduction $0.35 \mathrm{~kg}$ ). A reduction in fat mass and percentage body fat following light intervention was independent of seasonality trait and photoperiod. The results allowed the authors to conclude that bright light was the primary cause of fat reduction. Light is the strongest synchronizing agent for the circadian system, and therefore keeps most biological and psychological rhythms internally synchronized, which is important for optimum function. Circadian sleep-wake disruptions and chronic circadian misalignment, as often observed in psychiatric and neurodegenerative diseases, can be treated with light therapy [47].

One possible mechanism of the influence of light on physiological processes in the body is its effects on the neurohormonal system. For instance, light is known to inhibit the secretion of melatonin by the pineal gland [48]. In the study [49], the present results extend those in the literature by showing that light exposure in the morning can increase leptin and decrease ghrelin concentrations in sleep-restricted individuals although, again, the impact of morning light on leptin concentrations was more robust than on ghrelin concentrations. As leptin can suppress appetite, the authors suggest that light can be used as a nonpharmacological tool to clinically impact obesity [49]. Since in our study women were on a diet with a limited supply of energy substrates to the body during the whole course of exercise in combination with light exposure, this mechanism can hardly explain our findings.

In the study [50], the authors investigated the effect of short-wavelength light on cortisol content in saliva of sleep-restricted adolescents. Levels of cortisol, a hormone produced by the adrenal gland, follow a daily, 24-hour rhythm with concentrations reaching a minimum in the evening and a peak near rising time. In addition, 
cortisol levels exhibit a sharp peak in concentration within the first hour after waking: this is known as the cortisol awakening response (CAR). The authors demonstrated that the exposure to short-wavelength light in the morning significantly enhanced CAR compared to dim light. As a high CAR has been hypothesized to reflect the anticipation of stress, the authors suggest that morning exposure to short-wavelength light may be a simple, yet practical way to better prepare adolescents for an active day.

Other researchers previously also reported the stimulating effect of morning light exposure on cortisol level [51,52]. In [53], a cross-sectional association of the diurnal cortisol profile with markers of overall and abdominal obesity was found. These findings were independent of demographics, socioeconomic status, medications, and smoking. The authors noted a significant negative association of body-mass-index and waist circumference with awakening cortisol [53]. In [54], it has been shown that chronic feeding and sleep schedule disturbances are stressors that exert damaging effects on the organism, and are associated with evening hypercortisolism and increased insulin resistance. Consequently, changes in the circadian rhythm of cortisol and, probably other hormones and mediators can promote the development of disorders of hormonal regulation of energy metabolism and, correspondingly, pathology including obesity.

It can be supposed that light exposure in the morning, will also enhance the effectiveness of obesity correction by normalizing and/or increasing the amplitude of the circadian rhythm of cortisol. However, further research is needed in this area.

The advantage of using light exposure in the schemes of obesity correction is that this approach can be used in patients with concomitant diseases that contraindicate intense exercise. Exposure to bright artificial light can be used in various schemes of body weight correction and is especially important in winter when the period of insolation is short. The previously revealed antidepressant action of bright light [33] suggests the possibility of reducing the symptoms of "the diet-related depression" and other affective disorders caused by a low calorie diet.

Light exposures can be included in different programs of obesity correction through lifestyle modification, which will allow us to increase their effectiveness, especially in treatment of concomitant diseases at obesity [55]. Lifestyle modification aimed at reducing energy intake and increasing physical activity is the principal therapy for overweight and obese patients with type 2 diabetes. Even moderate weight loss in combination with increased activity can improve insulin sensitivity and glycemic control in patients with type 2 diabetes and prevent the development of type 2 diabetes in high-risk persons [56]. It is known that intensive, individualized programs have been successful, but are limited by time and resources. Sustainable lifestyle modification strategies are needed to address obesity and cardiovascular risk factors [57]. Inclusion of light exposures in such programs can be a very promising trend. Effect of bright light explore predominantly in women, because the problem of obesity in them has a great social importance. The effectiveness of bright light in the treatment of obesity in men needs further investigation. Gender differences probably would be determined not so much the severity of obesity, but the specialty of the fat depots topography, which have significant differences in men and women [58].

\section{CONCLUSION}

The use of complex method of obesity correction including the combination of exercise and bright light exposure, against the background of a low calorie diet, provides a greater reduction of body weight and adipose tissue mass than the use of a diet alone or a diet in combination with physical exercises. Inclusion of light exposures in a complex scheme of obesity correction increases the level of energy metabolism in the body, despite a long-term food restriction. We discuss the assumption that light exposure in the morning normalizes and/or increases the amplitude of the circadian rhythm of cortisol, which is one of the mechanisms of enhancing the effectiveness of obesity correction.

\section{ACKNOWLEDGEMENTS}

The authors would like to acknowledge of Scientific Centre of Clinical and Experimental Medicine director Prof. Vyacheslav A. Shkurupiy for support of the study.

\section{REFERENCES}

[1] World Health Organization (2000) Obesity: Preventing and managing the global epidemic. Report of a WHO consultation. World Health Organization Technical Report Series, 894, 1-253.

[2] Chrostowska, M., Szyndler, A., Hoffmann, M. and Narkiewicz, K. (2013) Impact of obesity on cardiovascular health. Best Practice \& Research Clinical Endocrinology \& Metabolism, 27, 147-156.

http://dx.doi.org/10.1016/j.beem.2013.01.004

[3] Felix-Redondo, F.J., Grau, M., Baena-Diez, J.M., Degano, I.R., De Leon, A.C., Guembe, M.J., Alzamora, M.T., Vega-Alonso, T., Robles, N.R., Ortiz, H., Rigo, F., Mayoral-Sanchez, E., Torno, M.J., Segura-Fragoso, A. and Frnandez-Berges, D. (2013) Prevalence of obesity and associated cardiovascular risk: the DARIOS study. BMC Public Health, 13, 542. http://dx.doi.org/10.1186/1471-2458-13-542

[4] Fujimoto, A., Hoteya, S., Iizuka, T., Ogawa, O., Mitani, 
T., Kuroki, Y., Matsui, A., Nakamura, M., Kikuchi, D., Yamashita, S., Furuhata, T., Yamada, A., Nishida, N., Arase, K., Hashimoto, M., Igarashi, Y. and Kaise, M. (2013) Obesity and gastrointestinal diseases. Gastroenterology Research and Practice, Article ID: 760574, 6 p.

[5] Pedersen, S.D. (2013) Metabolic complications of obesity. Best Practice \& Research Clinical Endocrinology \& Metabolism, 27, 179-193. http://dx.doi.org/10.1016/j.beem.2013.02.004

[6] Bjerkeset, O., Romundstad, P., Evans, J. and Gunnell, D. (2008) Association of adult body mass index and height with anxiety, depression, and suicide in the general population: The HUNT study. American Journal of Epidemiology, 167, 193-202. http://dx.doi.org/10.1093/aje/kwm280

[7] Ma, J. and Xiao, L. (2010) Obesity and depression in US women: Results from the 2005-2006 national health and nutritional examination survey. Obesity, 18, 347-353. http://dx.doi.org/10.1038/oby.2009.213

[8] Mather, A.A., Cox, B.J., Enns, M.W. and Sareen, J. (2009) Associations of obesity with psychiatric disorders and suicidal behaviors in a nationally representative sample. Journal of Psychosomatic Research, 66, 277-285. http://dx.doi.org/10.1016/j.jpsychores.2008.09.008

[9] Zhao, G., Li, C., Ford, E.S., Tsai, J., Dhingra, S.S., Croft, J.B., McKnight-Eily, L.R. and Balluz, L.S. (2012) Associations between Overall and Abdominal Obesity and Suicidal Ideation among US Adult Women. Journal of Obesity, Article ID: 263142, 9 p.

[10] Van Gaal, L.F., Mertens, I.L. and De Block, C.E. (2006) Mechanisms linking obesity with cardiovascular disease. Nature, 444, 875-880. http://dx.doi.org/10.1038/nature05487

[11] Bluher, M. (2012) Clinical relevance of adipokines. Diabetes \& Metabolism Journal, 36, 317-327. http://dx.doi.org/10.4093/dmj.2012.36.5.317

[12] Bluher, M. (2013) Adipose tissue dysfunction contributes to obesity related metabolic diseases. Best Practice \& Research Clinical Endocrinology \& Metabolism, 27, 163177. http://dx.doi.org/10.1016/j.beem.2013.02.005

[13] Chapman, C.D., Benedict, C., Brooks, S.J. and Schioth, H.B. (2012) Lifestyle determinants of the drive to eat: A meta-analysis. The American Journal of Clinical Nutrition, 96, 492-497. http://dx.doi.org/10.3945/ajcn.112.039750

[14] Heinonen, I., Helajarvi, H., Pahkala, K., Heinonen, O.J., Hirvensalo, M., Palve, K., Tammelin, T., Yang, X., Juonala, M., Mikkila, V., Kahonen, M., Lehtimaki, T., Viikari, J. and Raitakari, O.T. (2013) Sedentary behaviours and obesity in adults: The cardiovascular risk in young finns study. BMJ Open, 3, Article ID: e002901. http://dx.doi.org/10.1136/bmjopen-2013-002901

[15] Yeomans, M.R., Hails, N.J. and Nesic, J.S. (1999) Alcohol and the appetizer effect. Behavioural Pharmacology, 10, 151-161. http://dx.doi.org/10.1097/00008877-199903000-00004

[16] Caton, S.J., Ball, M., Ahern, A. and Hetherington, M.M. (2004) Dose-dependent effects of alcohol on appetite and food intake. Physiology \& Behavior, 81, 51-58. http://dx.doi.org/10.1016/j.physbeh.2003.12.017

[17] Luxassen, E.A., Rother, K.I. and Cizza, G. (2012) Interacting epidemics? Sleep curtailment, insulin resistance, and obesity. Annals of the New York Academy of Sciences, 1264, 110-134. http://dx.doi.org/10.1111/j.1749-6632.2012.06655.x

[18] Wadden, T.A., Butryn, M.L. and Wilson, C. (2007) Lifestyle modification for the management of obesity. Gastroenterology, 132, 2226-2238. http://dx.doi.org/10.1053/j.gastro.2007.03.051

[19] Strasser, B. (2013) Physical activity in obesity and metabolic syndrome. Annals of the New York Academy of Sciences, 1281, 141-159. http://dx.doi.org/10.1111/j.1749-6632.2012.06785.x

[20] Avenell, A., Broom, J., Brown, T.J., Poobalan, A., Aucott, L., Stearns, S.C., Smith, W.C., Jung, R.T., Campbell, M.K. and Grant, A.M. (2004) Systematic review of the long-term effects and economic consequences of treatments for obesity and implications for health improvement. Health Technology Assessment, 8, 1-182.

[21] (2013) Clinical guidelines on the identification, evaluation, and treatment of overweight and obesity in adults. http://www.nhlbi.nih.gov/guidelines/obesity/ob_home.htm

[22] Tsai, A.G. and Wadden, T.A. (2005) Systematic review: An evaluation of major commercial weight loss programs in the United States. Annals of Internal Medicine, 142, 56-66.

http://dx.doi.org/10.7326/0003-4819-142-1-200501040-0 $\underline{0012}$

[23] Bult, M.J.F., Van Dalen, T. and Muller, A.F. (2008) Surgical treatment of obesity. European Journal of Endocrinology, 158, 135-145.

http://dx.doi.org/10.1530/EJE-07-0145

[24] Lagerros, Y.T. and Rossner, S. (2013) Obesity management: what brings success? Therapeutic Advances in Gastroenterology, 6, 77-88.

http://www.sagepub.co.uk/journalsPermissions.nav. http://dx.doi.org/10.1177/1756283X12459413

[25] Tixeira, P.J., Going, S.B., Houtkooper, L.B., Cussler, E.C., Metcalfe, L.L., Blew, R.M., sardinha, L.B. and Lohman, T.G. (2004) Pretreatment predictors of attrition and successful weight management in women. International Journal of Obesity and Related Metabolic Disorders, 28, 1124-1133. http://dx.doi.org/10.1038/sj.ijo.0802727

[26] Bazzano, A.T., Zeldin, A.S., Diab, I.R., Garro, N.M., Allevato, N.A. and Lehrer, D. (2009) The healthy lifestyle change program: A pilot of a community-based health promotion intervention for adults with developmental disabilities. American Journal of Preventive Medicine, 37, 201-208.

[27] Jacka, F.N., Mykletun, A. and Berk, M. (2012) Moving towards a population health approach to primary prevention of common mental disorders. BMC Medicine, 10, 149. http://dx.doi.org/10.1186/1741-7015-10-149

[28] Jacka, F. and Berk, M. (2007) Food for thought. Acta Neuropsychiatrica, 19, 321-323. http://dx.doi.org/10.1111/j.1601-5215.2007.00246.x

[29] Faulconbridge, L.F., Wadden, T.A, Berkowitz, R.I., 
Sarwer, D.B., Womble, L.G., Hesson, L.A., Stunkard, A.J. and Fabricatore, A.N. (2009) Changes in symptoms of depression with weight loss: Results of a randomized trial. Obesity (Silver Spring), 17, 1009-1016.

http://dx.doi.org/10.1038/oby.2008.647

[30] Pinkhasov, B.B., Shorin, Yu.P. and Selyatitskaya, V.G. (2009) Nutritional behavior disorders and preferable dietary intakes in women with alimentary-constitutive obesity. Siberian Gerald of Psychiatry and Addiction Psychiatry, 1, 80-83.

[31] Luppino, F.S., De Wit, L.M., Bouvy, P.F.Stijnen, T., Cuijpers, P., Penninx, B.W. and Zitman, F.G. (2010) Overweight, obesity, and depression: A systematic review and meta-analysis of longitudinal studies. Archives of General Psychiatry, 67, 220-229.

[32] Fabricatore, A.N., Wadden, T.A., Higginbotham, A.J., Faulconbridge, L.F., Nguyen, A.M., Heymsfield, S.B. and Faith, M.S. (2011) Intentional weight loss and changes in symptoms of depression: A systematic review and meta-analysis. International Journal of Obesity (London), 35, 1363-1376 http://dx.doi.org/10.1038/ijo.2011.2

[33] Pinchasov B.B., Shurgaja, A.M., Grischin, O.V. and Putilov, A.A. (2000) Mood and energy regulation in seasonal and non-seasonal depression before and after midday treatment with physical exercise or bright light. Psychiatry Research, 94, 29-42.

http://dx.doi.org/10.1016/S0165-1781(00)00138-4

[34] Golden, R.N., Gaynes, B.N., Ekstrom, R.D., Hamer, R.M., Jacobsen, F.M., Suppes, T., Wisner, K.L. and Nemeroff, C.B. (2005) The efficacy of light therapy in the treatment of mood disorders: A review and meta-analysis of the evidence. The American Journal of Psychiatry, 162, 656-662. http://dx.doi.org/10.1176/appi.ajp.162.4.656

[35] Even, C., Schroder, C.M., Friedman, S. and Rouillon, F. (2008) Efficacy of light therapy in nonseasonal depression: A systematic review. Journal of Affective Disorders, 108, 11-23. http://dx.doi.org/10.1016/j.jad.2007.09.008

[36] Popper, C.W. (2013) Mood disorders in youth: Exercise, light therapy, and pharmacologic complementary and integrative approaches. Child and Adolescent Psychiatric Clinics of North America, 22, 403-441. http://dx.doi.org/10.1016/j.chc.2013.05.001

[37] Wadder, T.A., Foster, G.D., Sarwer, D.B., Anderson, D.A., Gladis, M., Sanderson, R.S., Letchak, R.V., Berkowitz, R.I. and Phelan, S. (2004) Dieting and the development of eating disorders in obese women: Results of a randomized controlled trial. American Journal of Clinical Nutrition, 80, 560-568.

[38] WHO (2008) Waist circumference and waist-hip ratio. Report of a WHO Expert Consultation, Geneva.

[39] Haugen, A.H., Chan, L.-N. and Li, F. (2007) Indirect calorimetry: A practical guide for clinicians. Nutrition in Clinical Practice, 22, 377-388. http://dx.doi.org/10.1177/0115426507022004377

[40] Tremblay, M.S., Colley, R.C., Saunders, T.J., Healy, G.N. and Owen, N. (2010) Physiological and health implications of a sedentary lifestyle. Applied Physiology, Nutrition, and Metabolism, 35, 725-740.

\section{http://dx.doi.org/10.1139/H10-079}

[41] Hamdy, O., Porramatikul, S. and Al-Ozairi, E. (2006) Metabolic obesity: The paradox between visceral and subcutaneous fat. Current Diabetes Reviews, 2, 367-373. http://dx.doi.org/10.2174/1573399810602040367

[42] Matsuzawa, Y. (2008) The role of fat topology in the risk of disease. International Journal of Obesity, 32, 83-92. http://dx.doi.org/10.1038/ijo.2008.243

[43] Heilbronn, L.K., De Jonge, L., Frisard, M.I., DeLany, J.P., Meyer, D.E.L., Rood, J., Nguyen, T., Martin, C.K., Volaufova, J., Most, M.M., Greenway, F.L., Smith, S.R., Williamson, D.A., Deutsh, W.A. and Ravussin, E. (2006) Effect of 6-month calorie restriction on biomarkers of longevity, metabolic adaptation and oxidative stress in overweight subjects. JAMA, 295, 1539-1548. http://dx.doi.org/10.1001/jama.295.13.1539

[44] Johannsen, D.L., Knuth, N.D., Huizenga, R., Rood, J.C., Ravussin, E. and Hall, K.D. (2012) Metabolic slowing with massive weight loss despite preservation of fat-free mass. The Journal of Clinical Endocrinology \& Metabolism, 97, 2489-2496. http://dx.doi.org/10.1210/jc.2012-1444

[45] Dunai, A., Novak, M., Chung, S.A., Kayumov, L., Keszei, A., Levitan, R. and Shapiro, C.M. (2007) Moderate exercise and bright light treatment in overweight and obese individuals. Obesity, 15, 1749-1757.

http://dx.doi.org/10.1038/oby.2007.208

[46] Danilenko, K.V., Mustafina, S.V. and Pechenkina, E.A. (2013) Bright light for weight loss: Results of a controlled crossover trial. Obesity Facts, 6, 28-38. http://dx.doi.org/10.1159/000348549

[47] Muinch, M. and Bromundt, V. (2012) Light and chronobiology: Implications for health and disease. Dialogues in Clinical Neuroscience, 14, 448-453.

[48] Zeitzer, J.M., Dijk, D.J., Kronauer, R.E., Brown, E.N. and Czeisler, C.A. (2000) Sensitivity of the human circadian pacemaker to nocturnal light: Melatonin phase resetting and suppression. The Journal of Physiology, 526, 695-702.

http://dx.doi.org/10.1111/j.1469-7793.2000.00695.x

[49] Figueiro, M.G., Plitnick, B. and Rea, M.S. (2012) Light modulates leptin and ghrelin in sleep-restricted adults. International Journal of Endocrinology, 2012, Article ID: 530726. http://dx.doi.org/10.1155/2012/530726

[50] Figueiro, M.G. and Rea, M.S. (2012) Short-wavelength light enhances cortisol awakening response in sleep-restricted adolescents. International Journal of Endocrinology, 2012, Article ID: 301935. http://dx.doi.org/10.1155/2012/301935

[51] Leproult, R., Colecchia, E.F., L’Hermite-Baleriaux, M. and Van Cauter, E. (2001) Transition from dim to bright light in the morning induces an immediate elevation of cortisol levels. Journal of Clinical Endocrinology and Metabolism, 86, 151-157. http://dx.doi.org/10.1210/jc.86.1.151

[52] Scheer, F.A.J.L. and Buijs, R.M. (1999) Light affects morning salivary cortisol in humans. Journal of Clinical Endocrinology and Metabolism, 84, 3395-3398. http://dx.doi.org/10.1210/jc.84.9.3395 
[53] Champaneri, S., Xu, X., Carnethon, M.R., Bertoni, A.G., Desantis, A.S., Roux A.D., Shrager, S. and Golden, S.H. (2013) Diurnal salivary cortisol is associated with body mass index and waist circumference: The multi-ethnic study of atherosclerosis. Obesity, 21, E56-E63. http://dx.doi.org/10.1002/oby.20047

[54] Bahijri, S., Borai, A., Ajabnoor, G., Khaliq, A.A., ALQassas, I., Al-Shehri, D. and Chrousos, G. (2013) Relative metabolic stability, but disrupted circadian cortisol secretion during the fasting month of Ramadan. PloS ONE, 8, Article ID: e60917. http://dx.doi.org/10.1371/journal.pone.0060917

[55] Ricanati, E.H.W., Golubic, M., Yang, D., Saager, L., Mascha, E.L. and Roizen, M.F. (2011) Mitigating preventable chronic disease: Progress report of the Cleveland Clinic's Lifestyle 180 program. Nutrition \& Metabolism, 8, 83. http://www.nutritionandmetabolism.com/content/8/1/83 http://dx.doi.org/10.1186/1743-7075-8-83

[56] Klein, S., Sheard, N.F., Pi-Sunyer, X., Wylie-Rosett, J.,
Kulkarni, K. and Clark, N.G. (2004) Weight management through lifestyle modification for the prevention and management of type 2 diabetes: Rationale and strategies. A statement of the American Diabetes Association, the North American Association for the Study of Obesity, and the American Society for Clinical Nutrition. American Journal of Clinical Nutrition, 80, 257-263.

[57] Pettman, T.L., Misan, G.M.H., Owen, K., Warren, K., Coates, A.M., Buckley, J.D. and Howe, P.R.C. (2008) Self-management for obesity and cardio-metabolic fitness: Description and evaluation of the lifestyle modification program of a randomized controlled trial. International Journal of Behavioral Nutrition and Physical Activity, 5, 53. http://dx.doi.org/10.1186/1479-5868-5-53

[58] Pinkhasov, B.B., Selyatitskaya, V.G., Karapetyan, A.R. and Astrakhantseva, E.L. (2012) Metabolic syndrome in men and women with upper or lower types of body fat distribution. Health, 4, 1381-1389.

http://dx.doi.org/10.4236/health.2012.412A200 